Short Communication

\title{
Development of a New Point of Care Testing for Electrochemical Detection of Glucose in Blood
}

\author{
Hui Wang ${ }^{1}$ and Kun Wang* \\ ${ }^{1}$ General Medicine, Liaoning Cancer Hospital and Institute, Shenyang, Liaoning 110041, China \\ ${ }^{2}$ Obstetrics and Gynecology, Peace Branch of Northern Theatre General Hospital, Shenyang, Liaoning \\ 110812, China \\ "E-mail: wangkgood@163.com
}

Received: 6 September 2021 / Accepted: 17 October 2021 / Published: 10 November 2021

Currently, blood glucose testing in the hospital is performed by an automated biochemistry analyzer in the laboratory and the point of care testing (POCT) meter. In this work, a POCT meter was fabricated with Pt-Pd nanowires. Combined with electrochemical synthesis techniques, an enzyme-free electrochemical sensor for glucose detection was constructed with a porous anodic alumina template with Pt-Pd standing on a gold electrode surface. Optimal conditions were determined in this work for glucose detection and also the sensitivity, stability, repeatability and interference resistance of the sensor for glucose detection were examined under simulated physiological conditions. In addition, the proposed POCT electrochemical sensor was adopted to compare the results with those of a biochemical instrument.

Keywords: Point of care; Electrochemical sensor; Glucose; Biochemical analyzer; Diabetes

\section{FULL TEXT}

(C) 2021 The Authors. Published by ESG (www.electrochemsci.org). This article is an open access article distributed under the terms and conditions of the Creative Commons Attribution license (http://creativecommons.org/licenses/by/4.0/). 